\title{
Novel Approach for Magnetic Nanoparticle-based Hyperthermia for Metastatic Cancer Treatment
}

\author{
Ricarina Rabinovitz, Ofer Shalev and Sarah Kraus* \\ New Phase Ltd, Petah Tikva 4934829, Israel \\ *Corresponding author: Sarah Kraus, New Phase Ltd, Petah Tikva 4934829, Israel
}

ARTICLE INFO

Received: 幽 December 04, 2020

Published: 幽 December 09, 2020

Citation: Ricarina Rabinovitz, Ofer Shalev, Sarah Kraus. Novel Approach for Magnetic Nanoparticle-based Hyperthermia for Metastatic Cancer Treatment. Biomed J Sci \& Tech Res 32(3)-2020. BJSTR. MS.ID.005254.

Keywords: Magnetic Hyperthermia; Iron Oxide Nanoparticles; Alternating Magnetic Field; Cancer; Enhanced Permeability and Retention Effect.

\begin{abstract}
The greater sensitivity of cancer cells to heat compared to healthy cells allows to destroy or make them more susceptible to treatment, using hyperthermia. Hyperthermia has been clinically used as an adjuvant therapy. Its limitations as a single therapy relate to the lack of dosimetry for clinical protocols, balancing between safety and efficacy, and the absence of homogenous heating surrounding cancer cells. Magnetic hyperthermia has been applied safely, offering a penetration depth that allows the induction of local heat in inner body tissues, while the use of magnetic nanoparticles, particularly Iron Oxide Nanoparticles (IONPs), allows for selective heating via the Enhanced Permeability and Retention (EPR) effect for tumor accumulation. The Sarah Nanotechnology system offers novel IONPs that heat in a magnetic field, with self-regulating temperature and a standardized protocol up scalable from animal models to human, thus overcoming the safety challenges of standard hyperthermia in addition to providing high efficacy.
\end{abstract}

Abbreviations: EPR: Enhanced Permeability and Retention, IONPs: Iron Oxide Nanoparticles, RF: Radio Frequency, MRI: Magnetic Resonance Imaging, SCLC: Small Cell Lung Cancer, AC: Alternating Current

\section{Mini Review}

Hyperthermia has been defined as the process of increasing the temperature of the body or a particular region of it beyond the threshold level set at a particular moment by the thermoregulatory system of an organism [1]. The stage of the cancer, the locations of malignancies and their depths inside the body, play a role when choosing the appropriate method of clinical hyperthermia application out of the existing three standard options: whole-body, regional, or local hyperthermia. While whole-body heat application is used to treat deep seated and disseminated malignancies, local or regional treatments deliver heat to localized or advanced cancer, respectively [2]. During the last decades, hyperthermia has been only used in combination with radiotherapy or chemotherapy mainly due to operational constraints and the incidence of harmful secondary effects that were found to affect the surrounding healthy tissues $[3,4]$.

Some thermal damage, such as the appearance of burns on external tissue, is a common side effect of treatment. This can be avoided by maximizing toxic effects on the tumor area and confining the heating to the volume of the tumor mass [1]. In addition to thermal damage, transient adverse effects such as vomiting, diarrhea, and nausea may appear. On rare and extreme occasions cardiac, vasculature and cerebral disorders may arise [5,6]. Since these occurrences are highly uncommon, and the ability to control, monitor, and understand hyperthermia and its effects has increased over recent years, its side effects are generally considered to be not serious, especially in comparison to other cancer treatments [5]. Several studies testing the clinical benefits of hyperthermia have been performed, providing evidence that hyperthermia is less efficacious when applied as a single therapy, with limiting factors such as the reproducibility of heat deposition into the tumor mass, the formation of hotspots [4,7], and the challenging measurement of the temperature within the tumor and its vicinity.

Nevertheless, hyperthermia has been demonstrated in trials to prolong life and decrease disease re-appraisal as an adjuvant therapy, damaging cancer cells and causing radiation and chemosensitization, with some tumors being more responsive than 
others [4]. Magnetic hyperthermia is based on the use of magnetic nanoparticles to induce local heat when a Radiofrequency (RF) magnetic field is applied, thereby providing an effective approach to destroy cancer cells [3]. Experimental studies examining the application of magnetic materials for hyperthermia date back to 1957 when Gilchrist et al. [8] heated various tissue samples using magnetic IONPs with a size of $20-100 \mathrm{~nm}$, exposed to a 1.2 $\mathrm{MHz}$ magnetic field, resulting in selective heating of lymphatic metastases. Henceforth, there have been several publications describing a variety of settings employing different types of magnetic nanoparticles, methods of encapsulation and delivery, and field strengths and frequencies [9].

Magnetic nanoparticles have demonstrated a wide range of applications including cell labelling and magnetic separation which is applied to many aspects of biomedical and biological research, use as contrast agents in Magnetic Resonance Imaging (MRI), targeted drug delivery, and hyperthermia-based cancer treatment [9]. The electromagnetic radiation used in magnetic hyperthermia is within the $\mathrm{RF}$ range (between several $\mathrm{kHz}$ and $\mathrm{MHz}$ ). This radiation shows enough penetration depth to access inner organs or tissues in the body and is relatively safe. The specificity of this technique is achieved by the higher sensitivity of cancer cells to temperature increases above $42^{\circ} \mathrm{C}$. The majority of cancer cells tend to die between $40^{\circ} \mathrm{C}$ and $43^{\circ} \mathrm{C}$ [10]. When cancer cells are subjected to this temperature range, they suffer irreversible damage, in a time and dose dependent manner, which includes changes in several biochemical processes that include, inhibition of DNA and RNA synthesis, DNA repair mechanisms, alterations in membrane fluidity, mitochondria structure, enhanced production of heat shock proteins that can affect thermotolerance and tumor immunogenicity, increased influx of reactive oxygen radicals, and others [10].

Because of the results that high temperature may produce in tissues, the use of temperatures above $50^{\circ} \mathrm{C}$ can be referred to as coagulation, and between $60^{\circ} \mathrm{C}$ to $90^{\circ} \mathrm{C}$ as thermal ablation [11] Several studies have demonstrated the therapeutic efficacy of magnetic hyperthermia in clinical trials [12] and animal models [13]. The challenge is how to deliver a sufficient amount of the magnetic particles to generate enough heat in the target using Alternating Current (AC) magnetic field conditions that are clinically acceptable and could be safely used in human patients. For example, a study in swine [14] reported the repeated use of the Kanzius non-invasive $\mathrm{RF}$ hyperthermia system (KNiRFH) which operates at $13.56 \mathrm{MHz}$, to treat liver cancer via targeted heating of tumors. Blood tests, MRI and specific absorption rates (SAR) level of the liver and fat were calculated to determine the system's heating efficacy and potential toxicities. No indications of aberrations, damage or toxicity were identified.

On theotherhand, at $38.5^{\circ} \mathrm{C}$, liver hyperthermiawas notachieved, once again demonstrating the difficulty to generate significant and homogenous local heating, in the absence of nanoparticles. The Sarah Nanotechnology System, developed by New Phase Ltd., is a medical device designed to treat metastatic stage IV Small Cell Lung Cancer (SCLC) and solid tumors through the delivery of thermal energy to malignant cells, thereby causing hyperthermiainduced cancer cell death at sub-ablative temperatures of up to $50^{\circ} \mathrm{C}$. The system involves two main components: (1) multicore Sarah Nanoparticles (SaNPs) containing encapsulated iron oxide and (2) an Electromagnetic Induction System (EIS). The SaNPs are administered intravenously to the patient and become localized via the EPR effect on cancer cells, which allows extravasation of the nanoparticles and enables the preferential retention of SaNPs in tumors due to their leaky vasculature and reduced lymphatic drainage [15]

Following delivery and accumulation of SaNPs on the malignant tissue, the patient undergoes regional AC magnetic field (AMF) application at $290 \pm 10 \% \mathrm{kHz}$. The SaNPs absorb the RF power and convert it to thermal energy, reaching a pre-determined temperature $\left(50 \pm 3^{\circ} \mathrm{C}\right)$, thereby heating the malignant cells and causing hyperthermic cancer cell death without harming healthy cells. The SaNP has an inherent ability that is both novel and unique to regulate its own temperature, preventing the occurrence of thermal ablation. The efficacy of Sarah Nanotechnology treatment has been extensively evaluated by New Phase in pre-clinical studies, using the murine $4 \mathrm{~T} 1$ breast cancer metastatic model in BALB/c mice. Several studies were conducted to determine the optimal conditions required for efficacy testing including, time intervals and exposure times for effective AMF application following SaNP administration. These studies have demonstrated a significant reduction in the number of lung metastases, their size and viability (data submitted for publication) suggesting that an adequate quantity of SaNP reaches the target organ and generates a sufficient thermal mass required to induce thermal damage to the cancerous tissue.

Phase I clinical reports have confirmed that the use of AMF is safe enough for clinical use, although optimization for the best clinical results is still needed. Johannsen et al. [16], have initially demonstrated the clinical use of hyperthermia for prostate cancer treatment and localized heating of prostate tumors following direct injection of magnetic nanoparticles with a size of 1-100nm and an AMF applicator (MagForce Nanotechnologies) operating at $100 \mathrm{kHz}$. Maximum temperatures of up to $55^{\circ} \mathrm{C}$ were achieved in the prostate. Two separate phase I studies, with and without brachytherapy, were conducted showing feasibility and good tolerability. Throughout the history of hyperthermia, a major issue has been the lack of a uniform dosimetry protocol. A thermal dose of $\mathrm{CEM} 43^{\circ} \mathrm{C}$ T90 (cumulative equivalent minutes at a standard targeted treatment temperature of $43^{\circ} \mathrm{C}$ obtained within $90 \%$ of the tumor volume) was found to be the most useful dosimetric parameter in clinical research, suggested as a treatment goal. 
This can be explained by the fact that cumulative delivering of at least $43^{\circ} \mathrm{C}$ to $90 \%$ of a tumor's volume for $\geq 10$ minutes corresponds to doubling of the probability for complete response and duration of response to hyperthermia [11]. Biodistribution and toxicity studies in murine and swine models, conducted by New Phase, have shown that in swine, SaNPs consistently accumulate also in the lungs, the target organ. The operation protocol of the EIS machine has been set to work at the same frequency (290 $10 \%$ $\mathrm{kHz}$ ) using 10 minutes intervals of discontinuous irradiation in both small and large animals. The same setup will be used in a first-inhuman clinical trial. New Phase has been able to upscale the dosing regimen from mice, to swine, and to humans in accordance with the FDA guideline for the estimation of the maximum safe starting dose in initial clinical trials for therapeutics in healthy human subjects [17].

Dose calculation was based on the no observed adverse effect level (NOAEL) principle for dosage scaling from animal to human or from animal to animal. No deleterious effects have been observed, even at high doses of $156 \%$ in swine (manuscript in preparation), and SaNP accumulation in healthy tissues does not induce any undesirable side or toxic effects and no thermal damage has been observed after whole-body (mice) or regional (swine) AMF application, with the SaNPs undergoing normal physiological excretion over time. The Sarah Nanotechnology uses a standardized protocol, up-scalable from mice to swine, to create a RF penetrative field that heats SaNPs, resulting in the localized, selective heating of cancer tissues, with results indicative of high safety and efficacy. Combined with the SaNP's distinct control of its temperature, the Sarah Nanotechnology overcomes many of the issues associated with hyperthermia and can be considered a potential novel therapeutic modality for cancer patients.

\section{References}

1. Dewhirst MW, Gibbs FA, Roemer RB, Samulski TV (2000) Hyperthermia. In: Gunderson LL, Tepper JE (eds.). Clin. Rad. Oncol. $1^{\text {st }}$ edn Chapter 14. New York, NY: Churchill Livingstone pp. 256-82.

2. Behrouzkia Z, Joveini Z, Keshavarzi B, Eyvazzadeh N, Aghdam RZ (2016) Hyperthermia: How can it be used? OMJ 31(2): 89-97.

\section{ISSN: 2574-1241}

DOI: 10.26717 /BJSTR.2020.32.005254

Sarah Kraus. Biomed J Sci \& Tech Res

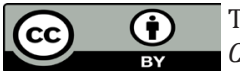

This work is licensed under Creative Commons Attribution 4.0 License

Submission Link: https://biomedres.us/submit-manuscript.php
3. Bañobre López M, Teijeiro A, Rivas J (2013) Magnetic nanoparticlebased hyperthermia for cancer treatment. Rep. Pract. Oncol. Radiother 18(6): 397-400

4. Baronzio G, Parmar G, Ballerini M, Szasz A, Baronzio M, et al. (2014) A brief overview of hyperthermia in cancer treatment. J Integr Oncol 3(1): 115.

5. Jha S, Sharma PK, Malviya R (2016) Hyperthermia: Role and risk factor for cancer treatment. Achieve Life Sci 10(2): 161-167.

6. Walter E, Carraretto M (2015) Getting hot and bothere. J Intensive Care Soc 16(3): 189-192.

7. Chatterjee DK, Diagaradjane P, Krishnan S (2011) Nanoparticlemediated hyperthermia in cancer therapy. Ther Deliv 2(8): 1001-1014.

8. Gilchrist RK, Medal R, Shorey WD, Hanselman RC, Parrott JC, et al. (1957) Selective inductive heating of lymph nodes Ann. Surg 146: 596-606.

9. Pankhurst QA, Connolly J, Jones SK, Dobson J (2003) Applications of magnetic nanoparticles in biomedicine. J Phys D: Appl Phys 36: R167-R181.

10. Pietrangeli P, Mondovì $\mathrm{B}$ (2006) On the biochemical basis of tumor damage by hyperthermia. In: Hyperthermia in cancer treatment: a primer. Gianfranco Baronzio and E Dieter Hager (Eds), Landes BioScience.

11. Chicheł A, Skowronek J, Kubaszewska M, Kanikowski M (2007) Hyperthermia-description of a method and a review of clinical applications. Rep Pract Oncol Radiother 12(5): 267-275.

12. Liu X, Zhang Y, Wang Y, Zhu W, Li G, et al. (2020) Comprehensive understanding of magnetic hyperthermia for improving antitumor therapeutic efficacy. Theranostics 10(8): 3793-3815.

13. Moroz P, Jones SK, Gray BN (2002) Magnetically mediated hyperthermia: current status and future directions. Int J Hyperthermia 18(4): 267-284.

14. Ho JC, Nguyen L, Law JJ, Ware MJ, Keshishian V, et al. (2017) Non-invasive radiofrequency field treatment to produce hepatic hyperthermia: Efficacy and safety in swine. IEEE J Transl Eng Health Med 5: 1500109.

15. Abdalla AME, Xiao L, Ullah MW, Yu M, Ouyang C, et al. (2018) Current challenges of cancer anti-angiogenic therapy and the promise of nanotherapeutics. Theranostics 8(2): 533-548.

16. Johannsen M, Thiesen B, Wust P, A Jordan (2010) Magnetic nanoparticle hyperthermia for prostate cancer. Int. J. Hyperthermia 26(8): 790-795.

17. (2005) USFDA. Guidance for Industry: Estimating the maximum safe starting dose in adult healthy volunteers. Rockville, MD: US Food and Drug Administration.

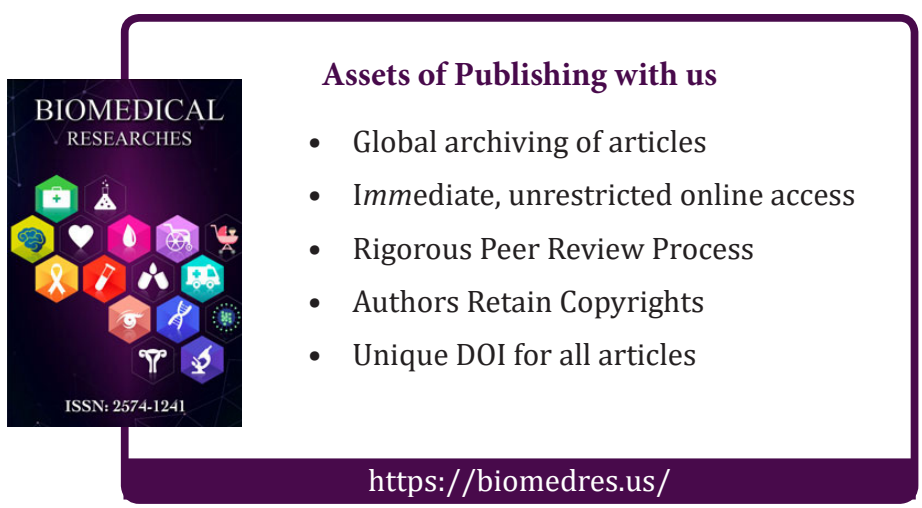

Copyright@ Sarah Kraus | Biomed J Sci \& Tech Res | BJSTR. MS.ID.005254. 